\title{
Development of Micromechanical Device on the Base of Two-Way Shape Memory Alloy Ribbon
}

\author{
A. Shelyakov ${ }^{a, *}$, N. Sitnikov ${ }^{a, b}$, A. Menushenkov ${ }^{a}$ And V. Fominski ${ }^{a}$ \\ ${ }^{a}$ National Research Nuclear University MEPhI (Moscow Engineering Physics Institute), \\ Kashirskoe shosse 31, Moscow 115409, Russian Federation \\ ${ }^{b}$ Federal State Unitary Enterprise "Keldysh Research Center", Onezhskaya St. 8, Moscow 125438, Russian Federation

\begin{abstract}
The aim of the present work is to fabricate and to research microgrippers (microtweezers) on the basis of the two-way shape memory effect. $\mathrm{Ti}_{50} \mathrm{Ni}_{25} \mathrm{Cu}_{25}$ alloy (at.\%) produced by melt-spinning technique in the form of layered amorphous-crystalline ribbons at around $40 \mu \mathrm{m}$ of thickness was used as the base material. The obtained structural composites were capable of executing reversible bending deformations in a heating/cooling cycle. A series of microtweezers with the gap adjustable in the range from 5 to $120 \mu \mathrm{m}$ was fabricated. The width of the gripping parts composed was 400-500 $\mu \mathrm{m}$ and their length was from 650 to $1300 \mu \mathrm{m}$ depending on the gap value. Optical and scanning electron microscopes were used to monitor the operation of the tweezers. It has been revealed that the response speed of the microgrippers essentially depends on the control temperature mode. The optimum control parameters provide the response time about $1 \mathrm{~s}$ by the operation both in the environment and in vacuum. The complete process of manipulating (gripping-holding-moving-releasing) the carbon fibers at the diameter 10 to $20 \mu \mathrm{m}$ with using the fabricated device was demonstrated.
\end{abstract}

DOI: 10.12693/APhysPolA.134.708

PACS/topics: $64.70 . \mathrm{kd}, 81.40 . \mathrm{Ef}, 81.30 . \mathrm{Kf}, 65.40 . \mathrm{De}, 85.85 .+\mathrm{j}$

\section{Introduction}

Progress of high technologies has been mainly governed by creation of radically new advanced materials with unique physical-mechanical properties. Among these materials, a special place is occupied by the so-called "smart" materials which had originated from synthesis of structural and functional materials together with integrating the control mechanism. Alloys with shape memory effect (SME) have proven to be some of the most interesting materials of this class. This results from unique and peculiar functional features and attendant effects of the shape memory alloys (SMAs): one-way SME, twoway SME (TWSME), a record recoverable strain and a great force by shape recovery, superelasticity, pseudoelasticity, high damping power, good chemical resistance and biocompatibility [1-4]. Remarkable properties of SMAs gave rise to a diversity of successful commercial applications in various industrial branches; first of all, these are medicine, energetics, aerospace technology, robotic science, biomedicine engineering [5-14]. Quite recently the successful use of the SMAs was demonstrated in micro-electro-mechanical systems (MEMS). The ability of the SME alloys to keep their unique characteristics at a micro-size level makes it possible to create on their base most miniature actuating devices: microgrippers, microswitches, microvalves, micropumps, microsensors [15-29]. In these units the actuators with reversible SME, manufactured entirely of SMAs as well as of composites based on SMAs, can be used.

*corresponding author; e-mail: AVShelyakov@mephi.ru
Double-contact devices, such as microtweezers, are very popular instruments for manipulation and research of individual microstructures [30-33]. The use of two tip effectors offers perceptible advantages for the attainment of more stable and reliable gripping of microobjects during transportation, installation and measurement.

The work is aimed at manufacturing and investigation of the microgrippers (microtweezers) based on composite amorphous-crystalline ribbons of the $\mathrm{TiNiCu}$ alloy, produced by rapid quenching of the melt and possessing the TWSME.

\section{Experimental}

As a material for the development of the microgripper, the $\mathrm{TiNiCu}$ alloy thin ribbons, produced by meltspinning technique, were used. The alloy ingots were made of super-purity metals with sixfold remelting in an arc furnace in an argon atmosphere. The ingots were melted down in a quartz crucible in a helium atmosphere and extruded through a narrow nozzle in the crucible to the surface of a quickly rotating copper wheel. Variation in quenching process parameters enabled to change the melt cooling rate in the range $10^{4}-10^{6} \mathrm{~K} / \mathrm{s}$, as well as the thickness and the width of the ribbons.

The microstructure of the samples was studied using the scanning electron microscope (SEM) FEI Quanta 600 FEG. Investigation into roughness of the ribbon surface was carried on the profilometer Veeco Dektak 150.

The microwelding technique with the pulse duration of $0.4 \mathrm{~s}$ at the voltage about $90 \mathrm{~V}$ was applied to join the two separate ribbons at manufacturing of the microtweezers. To form the microtweezers contour, the mechanical mini cutter SBR-8, operating on the model of guillotine and enabling the precision cutting of thin materials, was used. 
Operation of the microgripper, namely its closing and opening, was provided by heating and cooling it with a temperature control module based on the Peltier element. The module was governed by a controller, that is a precision programmable device with the bi-directional (heating and cooling) proportional-integral-differential (PID) regulation. The controller allows it to maintain a specified temperature with high accuracy and to fulfill the given program of heating/cooling in time.

To monitor a variation in the ribbon shape and the operation of the microtweezers, the optical microscope Digi Scope II v3, which makes it possible to carry out both video filming and photographing, was used. The microtweezers characteristics were investigated in the environment and in the SEM chamber.

\section{Results and discussion}

\subsection{Research and selection of the amorphous-crystalline ribbons of the TiNiCu alloy}

It is well known that rapidly quenched alloys of quasibinary system $\mathrm{TiNi}-\mathrm{TiCu}$ with a high content of copper (over 17 at.\%) possess a high liability to amorphisation and exhibit a clearly pronounced SME after heat treatment [34-38]. In this study the alloy with 25 at.\% copper was chosen for development of the microtweezers. Previously it has been ascertained that in this alloy at the melt cooling rates in the range $10^{4}-10^{6} \mathrm{~K} / \mathrm{s}$ the amorphous-crystalline ribbon with a sharp interface, separating the amorphous and crystalline states into layers, is formed, i.e., the ribbon is a laminated structural composite [39-41]. A series of samples of rapidly quenched composite ribbons, in which the thickness ratio between the amorphous and crystalline layers was varied due to the variation in the melt cooling rate, were produced in the work. The electron-microscope image of the representative cross-section of the amorphous-crystalline ribbon are shown in Fig. 1, the mean values of thicknesses of the crystalline and amorphous layers $\left(d_{c r}\right.$ and $d_{a m}$, respectively) are given in Table I. A decrease in the cooling rate from $6.5 \times 10^{5}$ down to $3.8 \times 10^{5} \mathrm{~K} / \mathrm{s}$ leads to an increase of the crystalline layer thickness from 5.40 to $9.80 \mu \mathrm{m}$.

All produced samples of the laminated amorphouscrystalline composites exhibit TWSME with bending deformation in the initial state after the quenching. Realization of the effect is illustrated in Fig. 2: at the heating above austenite transformation finish temperature, $A_{f}$, of the crystalline layer the sample assumes the shape close to a ring, and when cooled below the martensite transformation finish temperature, $M_{f}$ (to the ambient temperature), it passes into a straight state. In Ref. [39] nature of TWSME in the layered amorphous-crystalline ribbon is explained with the model, according to which the crystalline layer proves to be stretched after the quenching process. If such a composite be heated above the temperature $A_{f}$, then, due to realization of SME the crystalline layer would tend to compression, which can result in bending of the composite like a bimetallic plate. At the cooling, due to elasticity of the amorphous layer, the composite returns to the original state. It has been established that at varying temperature in the transformation interval the reversible change of the ribbon shape can be cyclically repeated more than 20000 times.

The minimum bending radius $R_{\text {min }}$ with manifestation of TWSME in the samples, prepared at different cooling rates, was measured. The reversible bending strain of the samples on realization of TWSME was estimated using the expression: $\xi=\left(d_{c r}+d_{a m}\right) /\left(2 R_{\min }\right)$. The obtained data for some samples are given in Table I.

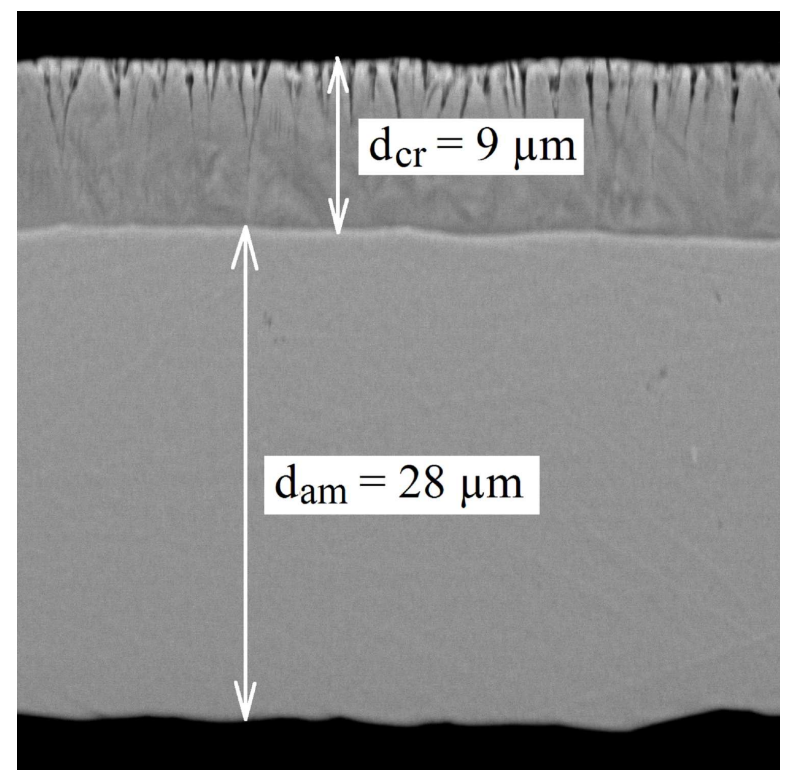

Fig. 1. SEM image of the characteristic cross-section of the layered amorphous-crystalline ribbons of the $\mathrm{Ti}_{50} \mathrm{Ni}_{25} \mathrm{Cu}_{25}$ alloy.

Parameters of the rapidly-quenched amorphous-crystalline composites with the different ratio between the thicknesses of amorphous and crystalline layers

\begin{tabular}{c|c|c|c|c|c|c}
\hline \hline No. & $d_{c r}[\mu \mathrm{m}]$ & $d_{a m}[\mu \mathrm{m}]$ & $d_{c r} / d_{a m}$ & $R_{\min }[\mathrm{mm}]$ & $\xi[\%]$ & $L_{\min }[\mathrm{mm}]$ \\
\hline 1 & 5.40 & 24.09 & 0.18 & 9.5 & 0.155 & 1.38 \\
2 & 6.52 & 25.20 & 0.21 & 9.3 & 0.171 & 1.37 \\
3 & 7.71 & 35.01 & 0.22 & 12.9 & 0.166 & 1.61 \\
4 & 6.56 & 24.71 & 0.23 & 8.8 & 0.178 & 1.33 \\
5 & 7.03 & 24.69 & 0.25 & 8.7 & 0.182 & 1.32 \\
6 & 9.80 & 29.96 & 0.33 & 8.1 & 0.242 & 1.28 \\
7 & 8.31 & 24.15 & 0.35 & 6.3 & 0.258 & 1.12
\end{tabular}


The carried out researches of the amorphouscrystalline ribbons make it possible to preliminarily evaluate the geometric parameters of the microtweezers on their basis. In this case, it is necessary to take into account the characteristic size of the investigated microobjects, which determines the initial magnitude of the microgripper gap. In this paper, the task was to create the microtweezers for manipulating objects up to $120 \mu \mathrm{m}$ in size. It is suggested that the microgripper will comprise two ribbons moving toward each other during the operation, therefore, each of them has to move its free end at least by $60 \mu \mathrm{m}$ to provide a full closing of the microgripper by the heating.

To select the optimum amorphous-crystalline ribbon of all the produced, the value of the ribbon displacement was estimated by means of the scheme shown in Fig. 2. Since the ribbon is bent during the heating, taking the shape close to a ring, the specified displacement $\Delta x$ of the ribbon at some distance $L$ away from the fixed point $A$ defines the minimum length $L_{\text {min }}$ of the working part of the microtweezers. The design formula for estimation may be derived from geometry of the scheme: $L=R \times \arccos (1-\Delta x / R)$. The values of $L_{\min }$ at $\Delta x=60 \mu \mathrm{m}$, obtained for the samples in hand, are presented in Table I.

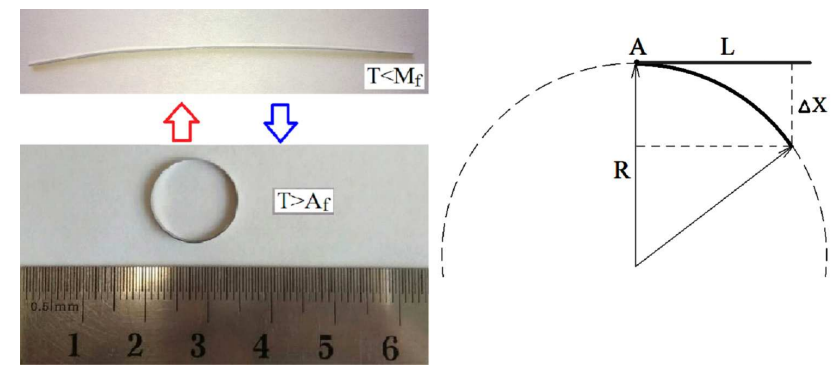

Fig. 2. The appearance of the ribbon exhibiting the TWSME, and scheme for calculating the ribbon displacement.

In addition, when choosing the ribbon, its quality was taken into account, first of all, its thickness homogeneity and surface roughness. The surface of the samples was examined over the width of the ribbon on its both sides; at least six measurements were made at different places. Typical profiles of each side of the ribbon are presented in Fig. 3. On the contact side of the ribbon there are surface defects associated with the surface quality of the quenching wheel, as well as with the possible influence of nonstationarity of the melt jet, for instance, with the possible ingress of gas into the area between the wheel and the melt or the appearance of whirls in the moving melt. The noncontact (free) side has a relatively lesser roughness, but its thickness from the ribbon centre to the edges decreases by several $\mu \mathrm{m}$. As a result, it has been obtained that for the contact surface of the ribbons the average deviation $R_{a}$ falls in the range from 0.63 to $0.85 \mu \mathrm{m}$, root-mean-square deviation $R_{q}=0.87-1.05 \mu \mathrm{m}$, for the noncontact surface $R_{a}=1.25-1.75 \mu \mathrm{m}, R_{q}=$ $1.35-1.62 \mu \mathrm{m}$.
The performed investigations and estimations have resulted in the selection of the sample No. 5, possessing the optimum combination of mechanical (shape memory) and surface properties for making the microtweezers. The width of the ribbon comprised $1200 \mu \mathrm{m}$, the measured temperatures of the start and the finish of shape recovery of the ribbon with the $\mathrm{SME}$ at heating were $T_{s}=(48.2 \pm 0.5){ }^{\circ} \mathrm{C}$ and $T_{f}=(57.1 \pm 0.5)^{\circ} \mathrm{C}$, respectively.

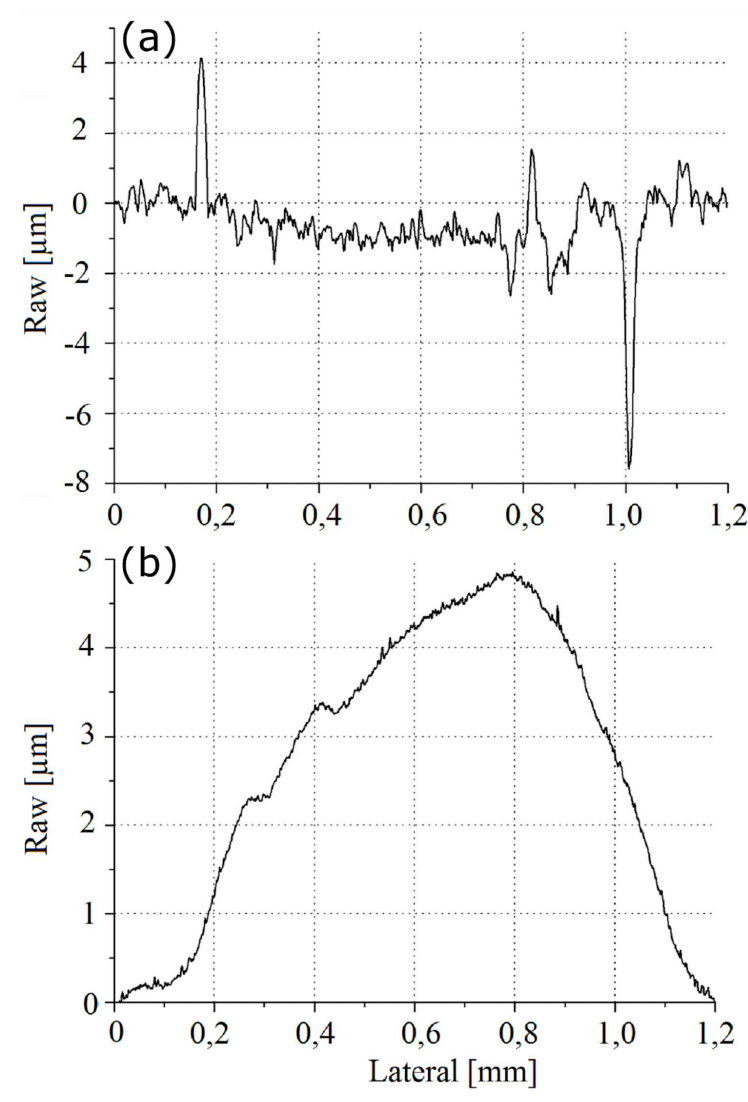

Fig. 3. The surface profiles of the contact (a) and the noncontact (b) sides of the $\mathrm{Ti}_{50} \mathrm{Ni}_{25} \mathrm{Cu}_{25}$ alloy ribbon.

\subsection{Manufacturing and investigation of the microtweezers}

For manufacturing of the microtweezers it was necessary to provide a joint of the two individual ribbons with a gap in such a way, that by heating they would bend in opposite direction and close, taking up fully the gap. The following procedure was used for this purpose. The two ribbons were superimposed, between them a spacer was placed. The spacer was made of the TiNiCu alloy amorphous ribbon, which did not exhibit SME with heating and cooling, and in so doing, did not inhibit any operation of the tweezers. Next the ribbons were joined by microwelding, forming a three-layer sandwich (Fig. 4a).

For the formation of the shape of the microtweezers and its miniaturization, an extra machining was made. The three-layer microtweezers produced were cut on both sides up to the required width $(400-500 \mu \mathrm{m})$. In so doing, the gripper had parallel faces of its moving parts (jaws) 
and enabled it to reach optimum characteristics. The thickness of the spacer set the initial value of the gap between the jaws, which varied in the work in the range from 5 to $120 \mu \mathrm{m}$. The length of the microgripper jaws depended on the gap size and comprised 650-1300 $\mu \mathrm{m}$ (Fig. 4b, c).

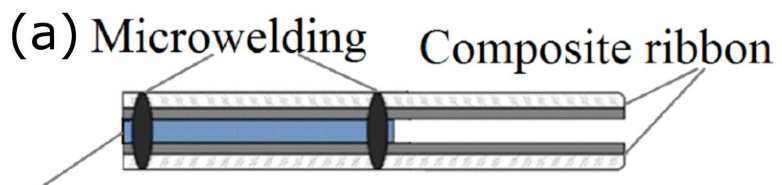

Amorphous ribbon
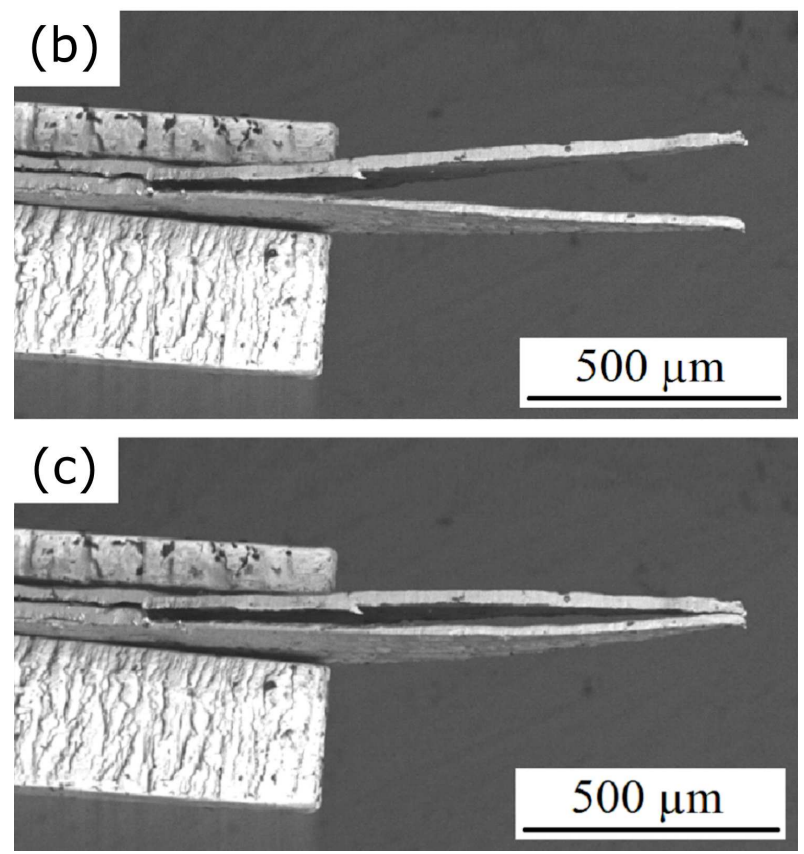

Fig. 4. The sketch of the microtweezers (a) and the SEM images of mirotweezers in the open (b) and closed (c) state.

To determine the time and temperature characteristics, the microtweezers were fastened in the temperature control module (TCM) between two silver plates installed on the Peltier element. The temperature was monitored by a thermistor mounted on one of the plates. The device construction provided a good thermal contact of all elements, and under the experimental conditions, there was virtually no temperature gradient between the location of the thermistor and the microtweezers.

The temperature dependence of the response time (closing and opening) of the device was measured in the SEM and in the environment using the procedure described in [42]. At first the initial temperature $T_{1}<M_{f}$ is set at the device, then the temperature is raised up to the preheating temperature $T_{2}<T_{s}$. To close the microtweezers the temperature is increased up to the temperature $T_{3}>T_{f}$. Finally, the temperature is decreased down to $T_{1}$, the gripper thereat opens. Then the operating cycle of the device can be repeated if necessary.
The correlation between the response time of the tweezers and the set temperature conditions was determined in the work. In so doing, both the temperature $T_{2}$ at the constant $T_{3}$, and the temperature $T_{3}$ at the constant $T_{2}$ were varied. It has been ascertained that with increasing the temperature $T_{3}$ to $71^{\circ} \mathrm{C}$ the response (closing) time of the microtweezers decreases down to $1 \mathrm{~s}$, and the further increase of $T_{3}$ does not result in a perceptible decrease of the response time. It has been shown that the preheating of the sample can be advisable, as the response time is prone to decrease with a growth of $T_{2}$. At the same time the attainment of the minimum response time should not lead to the false response, which could be observed at $T_{2}$ close to $T_{s}$, as well as to an excessive overheat of the device, caused by a too high temperature $T_{3}$.
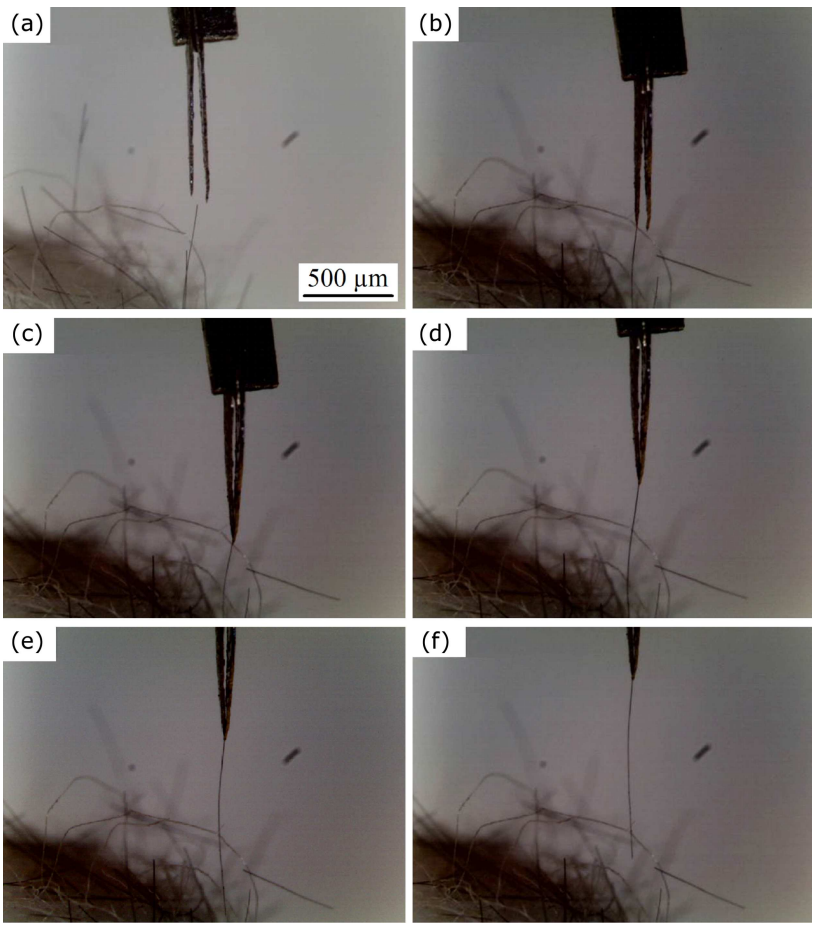

Fig. 5. The process of manipulation of the carbon fiber.

Based on the data obtained, the optimum operation mode of the microtweezers was selected: the preheating temperature $T_{2}=45^{\circ} \mathrm{C}$ and the overheating temperature $T_{3}=71^{\circ} \mathrm{C}$, the time of the closing thereat makes up $1.1 \mathrm{~s}$, the time of the opening - $1.7 \mathrm{~s}$. It is important to notice that in the vacuum conditions the time characteristics of the microtweezers have turned out to be the same, as in the environment.

To demonstrate the process of manipulation of microobjects, the TCM with the installed microtweezers was fastened on the mechanical 3D manipulator, making it possible to move the microtweezers at accuracy as high as $5 \mu \mathrm{m}$. As an object of the manipulation, a carbon fiber of diameter from 10 to $20 \mu \mathrm{m}$ was used. Video recording of the process was carried out with the opti- 
cal microscope, the camera report is presented in Fig. 5. Thus, using the developed microtweezers, the complete technological process of manipulating the microobject is realized: gripping-holding-moving-releasing.

\section{Conclusions}

The present work deals with the development and investigation of the microtweezers based on composite amorphous-crystalline ribbons of the $\mathrm{TiNiCu}$ alloy. The main results of the work reduce to the following:

1. The melt spinning technique was used to produce a series of layered amorphous-crystalline composites of the $\mathrm{Ti}_{50} \mathrm{Ni}_{25} \mathrm{Cu}_{25}$ alloy (at.\%), exhibiting the two-way shape memory effect, with the different thickness ratio of the amorphous and crystalline layers.

2. The produced structural composites were a base for manufacturing of a series of microtweezers with the gap adjustable in the range from 5 to $120 \mu \mathrm{m}$, the width of the gripping parts was $400-500 \mu \mathrm{m}$ and their characteristic length was from 650 to $1300 \mu \mathrm{m}$ depending on the gap value.

3. It has been revealed that the time characteristics of the microtweezers essentially depend on the control temperature regime. The optimum control parameters provide the response time (closing and opening) of the microtweezers as high as $1.1 \mathrm{~s}$ and $1.7 \mathrm{~s}$, respectively, by the operation both in the environment and in vacuum.

4. The feasibility to manipulate microobjects (the carbon fibers at the diameter 10 to $20 \mu \mathrm{m}$ ) with using the fabricated device was demonstrated. The microtweezers developed may be used, in particular in microelectronics, robotics or microbiology, for the gripping and the moving of microobjects of various origin of size 5 to $120 \mu \mathrm{m}$.

\section{Acknowledgments}

The reported study was supported by RFBR according to the research project 16-32-60105.

\section{References}

[1] Advances in Shape Memory Materials, Eds. Q. Sun, R. Matsui, K. Takeda, E.A. Pieczyska, Springer, Berlin 2017.

[2] J.M. Jani, M. Leary, A. Subic, M.A. Gibson, Mater. Des. 56, 1078 (2014).

[3] K. Otsuka, X. Ren, Progr. Mater. Sci. 50, 511 (2005).

[4] S.A. Fadlallah, N. El-Bagoury, S.M.F. Gad El-Rab, R.A. Ahmed, G. El-Ousamii, J. Alloys Comp. 583, 455 (2014).

[5] J. Van Humbeeck, Mater. Sci. Eng. A 273-275, 134 (1999).
[6] D. Stoeckel, Mater. Des. 11, 302 (1990).

[7] C. Bil, K. Massey, E.J. Abdullah, J. Intell. Mater. Syst. Struct. 24, 879 (2013).

[8] D.J. Hartl, D.C. Lagoudas, J. Aerospace Eng. 221, 535 (2007).

[9] M. Kheirikhah, S. Rabiee, M. Edalat, in: RoboCup 2010: Robot Soccer World Cup XIV, Eds. J. Ruizdel-Solar, E. Chown, P. Plöger, Springer, Berlin 2011, p. 206.

[10] L. Petrini, F. Migliavacca, J. Metall. 2011, 501483 (2011).

[11] C. Song, Open Med. Dev. J. 2, 24 (2010).

[12] N.B. Morgan, Mater. Sci. Eng. A 378, 16 (2004).

[13] G. Song, N. Ma, H.-N. Li, Eng. Struct. 28, 1266 (2006).

[14] L. Sun, W.M. Huang, Z. Ding, Y. Zhao, C.C. Wang, H. Purnawali, C. Tang, Mater. Des. 33, 577 (2012).

[15] H. Kahn, M.A. Huff, A.H. Heuer, J. Micromech. Microeng. 8, 213 (1998).

[16] M. Tomozawa, S. Miyazaki, J. Intell. Mater. Syst. Struct. 17, 1049 (2006).

[17] Y. Fu, W. Huang, H. Du, Surf. Coat. Technol. 145 107 (2001).

[18] I. Chakraborty, W.C. Tang, D.P. Bame, T.K. Tang, Sens. Actuators A 83, 188 (2000).

[19] B. Kim, M.G. Lee, Y.P. Lee, Y. Kim, G. Lee, Sens. Actuators A 125, 429 (2006).

[20] J.J. Gill, D.T. Chang, L.A. Momoda, G.P. Carman, Sens. Actuators A 93, 148 (2001).

[21] A. Nespoli, S. Besseghini, S. Pittaccio, E. Villa, S. Viscuso, Sens. Actuators A 56, 149 (2010).

[22] M. Kohl, Shape Memory Microactuators (Microtechnology and MEMS), Springer, Berlin 2010.

[23] Y.Q. Fu, J.K. Luo, A.J. Flewitt, W.M. Huangetal, Int. J. Computat. Mater. Sci. Surf. Eng. 2, 208 (2009).

[24] Q. Pan, C. Cho, Sensors 7, 1887 (2007).

[25] P.M. Chan, C.Y. Chung, K.C. Ng, J. Alloys Comp. 449, 148 (2008).

[26] Y. Bellouard, Mater. Sci. Eng. A 481-482, 582 (2008).

[27] T. Mineta, K. Kasai, Y. Sasaki, E. Makino, T. Kawashima, T. Shibata, Microelectron. Eng. 86 , 1274 (2009)

[28] H.J. Zhang, C.J. Qiu, Mater. Sci. Eng. A 438-440, 1106 (2006).

[29] N. Sitnikov, R. Rizakhanov, A. Shelyakov, Russian Federation Patent RU 2617841, December 23, 2015.

[30] H. Zhao, M. Chang, X. Liu, J.L. Gabayno, H.T. Chen, J. Micromech. Microeng. 24, 095012 (2014).

[31] K.J. Briston, A.G. Cullis, B.J. Inkson, J. Micromech. Microeng. 20, 015028 (2010).

[32] J. Chang, B.-K. Min, J. Kim, S.-J. Lee, L. Lin, Smart Mater. Struct. 18, 065017 (2009).

[33] W.M. Huang, J.P. Tan, X.Y. Gao, J.H. Yeo, J. Microlithogr. Microfabr. Microsyst. 2, 185 (2003). 
[34] A.V. Shelyakov, N.M. Matveeva, S.G. Larin, in: Shape Memory Alloys: Fundamentals, Modeling and Industrial Applications, Eds. F. Trochu, V. Brailovski, A. Galibois, Canadian Inst. of Mining, Metallurgy and Petrolium, Quebec City 1999, p. 295.

[35] A.V. Shelyakov, Yu.A. Bykovsky, N.M. Matveeva, Yu.K. Kovneristy, J. Phys. IV (France) C8, 713 (1995).

[36] P.L. Potapov, S.E. Kulkova, A.V. Shelyakov, K. Okutsu, S. Miyazaki, D. Schryvers, J. Phys. IV (France) 112, 727 (2003).

[37] S.H. Chang, S.K. Wu, H. Kimura, Intermetallics 15 233 (2007).

[38] J. Morgiel, E. Cesari, J. Pons, A. Pasko, J. Dutkiewicz, J. Mater. Sci. 37, 5319 (2002).
[39] A. Shelyakov, N. Sitnikov, S. Saakyan, A. Menushenkov, R. Rizakhanov, A. Korneev, Mater. Sci. Forum 738-739, 352 (2013).

[40] A. Irzhak, D. Zakharov, V. Koledov, G. Lebedev, A. Mashirov, V. Afonina, K. Akatyeva, V. Kalashnikov, N. Sitnikov, N. Tabachkova, A. Shelyakov, V. Shavrov, J. Alloys Comp. 586, S464 (2014).

[41] A.V. Shelyakov, N.N. Sitnikov, A.P. Menushenkov, R.N. Rizakhanov, A.A. Ashmarin, Bull. Russ. Acad. Sci. Phys. 79, 1134 (2015).

[42] A. Shelyakov, D. Rozhkov, N. Sitnikov, A. Menushenkov, A. Timofeev, M. Berezin, Mater. Today Proc. 4, 4870 (2017). 